\title{
Representation and Acquisition of Linguistic Knowledge: Perspectives of the Rationalist and the Empiricist
}

\author{
Edward Owusu1,2, Solomon Ali Dansieh ${ }^{3}$, Samuel Kyei Adoma² \\ ${ }^{1}$ Directorate of Quality Assurance and Academic Planning, Sunyani Technical University, Sunyani, Ghana \\ ${ }^{2}$ Department of Communication Studies, Sunyani Technical University, Sunyani, Ghana \\ ${ }^{3}$ Department of General and Liberal Studies, and Directorate of Research and Academic Programmes, Wa Technical University, \\ Wa, Ghana \\ Email: edwardowusu@minister.com
}

How to cite this paper: Owusu, E., Dansieh, S.A. and Adoma, S.K. (2021) Representation and Acquisition of Linguistic Knowledge: Perspectives of the Rationalist and the Empiricist. Open Access Library Journal, 8: e7265.

https://doi.org/10.4236/oalib.1107265

Received: February 24, 2021

Accepted: April 10, 2021

Published: April 13, 2021

Copyright $\odot 2021$ by author(s) and Open Access Library Inc.

This work is licensed under the Creative Commons Attribution International License (CC BY 4.0).

http://creativecommons.org/licenses/by/4.0/

\begin{abstract}
In second language teaching and learning, acquisition of knowledge is a multidimensional concept. Several concepts have been advocated by different theorists. All the theories are grounded in peculiar philosophical underpinnings that seem to have sound bases. This current paper critically examines the theories of representation and acquisition of linguistic knowledge from the standpoints of the rationalists and the empiricists. The method used in this paper is qualitative content analysis. With this analysis, the paper is segmented into five themes. These are the introduction, the method, review of literature, pedagogical perspective, and the conclusion. The literature review critically examines the viewpoints of the rationalists and the empiricists on the ultimate source of knowledge, mechanisms of acquisition, and characteristics of the initial state. These parts constitute the pivotal thematic areas of the main argument of the two schools of thoughts.
\end{abstract}

\section{Subject Areas}

Education

\section{Keywords}

Rationalism, Empiricism, Theory of Knowledge, Mechanisms of Acquisition, Source of Knowledge, Initial State, Language Acquisition Device

\section{Introduction}

In philosophy, epistemology is the theory of knowledge, especially with regards 
to its methods, validity, and scope. Accordingly, epistemology becomes an umbrella nomenclature used to elucidate the study of philosophical complications underlying theories of knowledge. In language acquisition, several theories of knowledge have been advanced. Rationalism and empiricism are two disparate philosophical schools of thought projecting various concepts of acquisition of knowledge. The similarities of these two schools of thought emanate from the fact that they both attempt to establish the source of knowledge claims, and to determine how humans form concepts and ideas.

The rationalist and the empiricist differ in their approaches to the representation and acquisition of linguistic knowledge [1]. These two classically contradictory approaches diverge more especially in their views of: 1) the ultimate source of knowledge, 2) mechanisms of acquisition, and 3) characteristics of the initial state. This current paper critically examines the differences and similarities of rationalism and empiricism in these three areas.

\section{Method}

The method used for this paper is qualitative content analysis. Qualitative content analysis is one of the several qualitative existing methods for analyzing data and interpreting connotational and denotational sense of data [2]. A requirement for successful content analysis is that data that describe the research phenomenon can be reduced to themes [3] [4] [5]. Breaking the data into themes helps the writer to examine the units of the data in a systematic way. Therefore, the main data the current paper espouses is representation and acquisition of linguistic knowledge from the outlook of the rationalist and the empiricist. The paper examines the data from three sub-themes of the ultimate source of knowledge, mechanisms of acquisition, and characteristics of the initial state.

\section{The Ultimate Source of Knowledge}

On the ultimate source of knowledge, rationalists think that the mind is the ultimate source of knowledge, not the external input. To them, grammar in the mind applies to, and to some degree determines, linguistic experience [1]. Thus, at birth, every individual with the right senses has linguistic knowledge. Therefore, to them, knowledge is already in the mind and does not depend on external input. The empiricists on the other hand believe that "infant is born as a tabula rasa" [1]. Tabula rasa is a Latin term for nonexistence of preconceived ideas or predetermined goals. Empiricists believe that at birth, human beings have no innate ideas, and that all ideas generated are from external input processes. For example, if two identical twins were separated at birth and taken to two different environments, various external input processes would affect their linguistic knowledge over time. so, if the separation of the two twins mentioned earlier, is such that one is exposed to an environment where English is the native language, that child is likely to acquire the pragmatics, syntax, morphology, semantics, phonetics, and phonology of that variety of English with little or less effort. On 
the other hand, if the other twin child settles in an environment where English is spoken as a second or third language, the environmental factors would push the child to all acquire the linguistic features of the variety of English spoken in that environment with time. So, while rationalists believe that linguistic knowledge is triggered by the structure of the mind, which is internal, the empiricists are of the view that ultimate source of knowledge is external, and is triggered by environmental input.

\section{Mechanisms of Acquisition}

Rationalists and empiricists, again, differ in terms of mechanisms of acquisition. Rationalists opine that the essential mechanism of knowledge acquisition lies in the mind's ability to generate what is perceived as input, and to deduce new knowledge [1]. Thus, rationalists subscribe to this classical theory that claims that knowledge is acquired or derived from the structure of the human mind; and that "[a]nything intelligible to us must be made so by rules of the mind"; "appearances in general are nothing outside our representations" [6] [7].

Simply put, if a child is knowledgeable, he is knowledgeable from within (the mind). The ideas the child possesses are not acquired from outside. In respect of this hypothesis, most people who subscribe to this theory believe that if a person is knowledgeable in a certain field of study, the tendency that the person's offspring would be knowledgeable in that field is high. To these believers of this theory, the external factors do not matter at all. For example, if someone plays a musical instrument, his or her children could also play the same or similar musical instrument since that knowledge is already in the genes of the children

Empiricists, however, think that knowledge is derived from experiences of the "outside world" [1]. Thus, ideas are only acquired through experience, and not through innate ideas. Empiricists as a result reject the idea of innate knowledge because, for example, if babies have this innate knowledge, why do they not exhibit it right after birth? Why can't they talk or walk or play right after birth? To them babies learn to accomplish all these simple tasks after they had had experience from the environment. To empiricist, for example, if you play a musical instrument, it does not necessarily mean your offspring will also play this instrument. For the offspring to be competent in that musical instrument, first, he or she has to be exposed to that instrument, learn the theories of it before the child can be competent. So, the environment matters in acquisition of knowledge.

\section{Characteristics of the Initial State}

Concerning characteristics of the Initial State, a rationalist perspective proposes some innate competence. According to them (rationalists) the Initial State is biologically programmed prior to experience in such a way that it makes linguistics experience possible and constrains its form [6]. For example, Chomsky proposed and investigated a classical theory of the Initial State that is, the "Language 
Faculty" of the human species and concludes that:

"[T]here is a specific faculty of the mind/brain that is responsible for the use and acquisition of language, a faculty with distinctive characteristics that is apparently unique to the species in essentials" [8].

The Initial State, or the Language Faculty "serves the two basic functions of rationalist theory: it provides a sensory system for the preliminary analysis of linguistic data, and a schematism that determines, quite narrowly, a certain class of grammars" [9]. Thus, rationalists believe that the Initial State has two characteristics: 1) the Language Faculty, which supplies a mechanism for the primary examination of language and 2) a faculty that establishes narrowly, a certain type of grammars.

By inference, one realizes that the rationalists assume that the mind has the capacity to accommodate several types of grammar. So, for instance, if you are a polyglot with equal competence in two languages, and you happen to settle in another speech community, the minds of your offspring have the capacity to accommodate a third or even fourth language. To the rationalist, this is highly characteristic of the mind. Thus, by nature the Language Faculty is competent.

The position of the rationalists is supported by their hypothesis known as the Innateness Hypothesis, which states that: “... the mind/brain provides a way to identify and extract the relevant information by means of mechanisms of some sort that are part of its biologically determined resources" [10]. Consequently, rationalists believe that biologically, the mind has a faculty that houses language and also aids in processing language and knowledge. This hypothesis is in consonance with Chomsky's Language Acquisition Device ( $L A D)$. The LAD, to Chomsky, is "logically explicated the preconditions for acquiring linguistics knowledge on the basis of projection from input" [11] [12]. Thus, children are born with a hard-wired device, LAD, which is situated in the brain. This LAD, according to Chomsky, helps children to acquire language and for the LAD to function, it requires primary linguistic data which will serve as a trigger. So characteristically, everyone's Initial State, has this LAD. But, as one grows the LAD diminishes; and this explains why it is easier for children to acquire new language(s) and relatively difficult for adults to execute the same action.

However, the LAD had its challenges. For example, the third component (i.e. some initial delimitation of a class of possible hypotheses about language structure) was often interpreted as implying that a predetermined set of "specific language grammars" (for example, English, Swahili, Sinhala, Akan, or Hindi) were innate; and that these merely needed to be "selected from," raising the question of how these grammars arise and how children judged whether the data were "compatible" with the grammar hypothesized' [4]. The question, therefore, is how many grammars are in the Language Faculty? Consequently, Chomsky moved the theory of the Language Faculty from LAD to another hypothesis known as the Universal Grammar (UG) which says that: "Universal grammar is part of the genotype specifying one aspect of the initial state of the human mind 
and brain" [1].

Conversely, the empiricists, on the characteristics of the Initial State, have attempted to explain language acquisition without attributing to children abstract linguistic knowledge [8]. They have supported their assertion with the Usage-Based Account Hypothesis (which states that language acquisition is based on item by item imitation learning [13]. Thus, the child gains linguistic knowledge by imitation of sound around the environment. So, learning plays a major role in the child's acquisition of language; the society and the environment also matter if the learner would perform.

Another hypothesis which has been propagated by empiricists is the Functionalism and Competition Model (F \& CM), which proposes "that Universal Grammar can ultimately be explained without recourse to a special 'language organ' that takes up where cognition leaves off' [14]. This hypothesis attempts to rectify a lack of emphasis on learning in the rationalist perspective. For example, if one wants to learn some linguistic knowledge of syntax, phonetics, morphology or semantics, one has to take time and learn them. This linguistic knowledge is not necessarily in the Language Faculty. Empiricists' view on the Initial State, Language Faculty, has led to a kind of linguistics known as Cognitive Linguistics, which claims that knowledge of language arises out of language use. For example, the more an L2 learner uses English language, the more English language knowledge he acquires. This, as a result, denies the fact that there is an autonomous linguistic faculty in the mind.

\section{Pedagogical Perspective}

Many philosophical perspectives about adult education practices and how adults learn languages exist in the literature. Adult learners possess many characteristics that affect their language learning. The language teacher or instructor should understand these characteristics and develop instruction that complements and allows these characteristics to grow. Malcom Knowles developed a model with the underlying assumption that teaching adults differ from teaching children. Knowles' Andragogical Model has some assumptions. A major characteristic of adult learners is that they tend to be more self-directing. Therefore, the language teacher should provide some guided and independent practice tasks in the language classroom. This is because, by adulthood, individuals might have developed an independent view of themselves and their learning strategies.

Adults, by definition are responsible people who seek to build their self-esteem through learning experiences they believe are useful and that enhance their competence. Consequently, the language teacher should strive hard to identify these self-esteem variables of learners and develop appropriate tasks to meet their goals. Tasks such as imitative speaking, intensive speaking, oral presentations, and responsive speaking may be useful in speaking and pronunciation lessons. By nature, most adults desire to achieve success in the tasks instructors give them. Again, adult language learners accumulate a large reservoir of expe- 
rience that affects their ability to perceive, process and use information. Their experience also serves as a foundation for gaining additional knowledge including language acquisition. Thus, most adult learners attach more importance to learning gained from experience than that acquired passively. Therefore, it is the duty of the language instructor to ascertain the linguistic background of the language learner. This would enable the instructor to know the strategies to deploy in dealing with language-related challenges that arise. For example, some of these challenges may be interferences emanating from the use of the learner's first language, the nature of the basic school the learner attended, and environmental factors. It is important to note that the readiness of the adult second language learner to learn a new task is affected by a need to know or do something. Also, adults are motivated to learn mostly by internal or intrinsic factors as opposed to external or extrinsic factors. They choose education as a means of increasing their competence [15]. Consequently, the language teacher should endeavour to develop strategies that would boost both the intrinsic and extrinsic motivational factors of learners. Information such as importance of acquiring a second or a third language, the international perspective or function of a particular language, and occupational prospective of languages should be highlighted. Passing on linguistic knowledge to students in tertiary institutions would require that these fundamental pedagogical strategies be taken into consideration.

\section{Conclusion}

In concluding this current paper, it is imperative to note that the rationalist believes in innateness which argues that the mind is the ultimate source of knowledge, and not the input. Thus, the rationalist subscribes to the classical theory that knowledge is acquired or derived from the structures of the human mind. This position is supported by Chomky's LAD theory. The empiricist, on the other hand, argues that at birth, human beings have no innate ideas and that all ideas generated emanate from external processes. The environment, to the empiricists, plays a major role in this external process. Thus, to the empiricist knowledge is derived from the external world through experience. These two diametrically opposed positions of the rationalist and the empiricist have generated a lot of theories, either supporting the rationalist's or the empiricist's position. One of such studies is Piaget's theory of cognitive development, which categorizes the nature and development of human intelligence into four categories of sensorimotor, preoperational, concrete operational, and formal operational [16]. It is worthy to note that rationalism and empiricism have some pedagogical implications which have been highlighted in Section 6 of this current paper. Language teachers who attempt to facilitate the learning of linguistic knowledge of language learners should understand that the minds of learners are unique by nature. Thus, language teachers who appreciate the uniqueness of the minds of learners can comprehend why some learners are by nature fast, and why some are slow learners. Again, the environments where the various learners come 
from may have several influences on the learners' language ability. If language teachers can comprehensively fathom the tenets of rationalism and empiricism, they would not coerce learners in producing some structure which may be challenging for some learners. With a complete understanding of the tenets of rationalism and empiricism, language teachers could develop and deploy mixed strategies that would assist different learners (with different needs) in their quest to acquire or learn a second or even a third language.

\section{Conflicts of Interest}

The authors declare no conflicts of interest regarding the publication of this paper.

\section{References}

[1] Lust, C.B. (2006) Child Language Acquisition and Growth. Cambridge University Press, Cambridge. https://doi.org/10.1017/CBO9780511803413

[2] Schreier, M. (2012) Qualitative Content Analysis in Practice. Sage, Thousand Oaks, CA.

[3] Cavanagh, S. (1997) Content Analysis: Concepts, Methods and Applications. Nurse Researcher, 4, 5-16.

[4] Elo, S. and Kyngäs, H. (2008) The Qualitative Content Analysis Process. Journal of Advanced Nursing, 62, 107-115. https://doi.org/10.1111/j.1365-2648.2007.04569.x

[5] Hsieh, H.-F. and Shannon, S. (2005) Three Approaches to Qualitative Content Analysis. Qualitative Health Research, 15, 1277-1288. https://doi.org/10.1177/1049732305276687

[6] Kant, I. (1781) The Critique of Pure Reason. Floating Press, Auckland.

[7] Beardsley, M.C., Ed. (1960) The European Philosophers from Descartes to Nietzsche. Modern Library, New York.

[8] Chomsky, N. (1987) The Chomsky Reader. Pantheon Books, New York.

[9] Chomsky, N. (1975) The Logical Structure of Linguistic Theory. Plenum Press, New York.

[10] Chomsky, N. (1988) Language and Problems of Knowledge. MIT Press, Cambridge, MA.

[11] Chomsky, N. (1984) Modular Approaches to the Study of the Mind. San Diego State University Press, San Diego, CA.

[12] Chomsky, N. (1999) On the Nature, Use, and Acquisition of Language. In: Ritchie, W.C. and Bhatia, T.K., Eds., Handbook of Child Language Acquisition, Academic Press, San Diego, CA, 33-54.

[13] Tomasello, M. (2000) The Cultural Origins of Human Cognition. Harvard University Press, Cambridge, MA.

[14] Bates, E.A. and MacWhinney, B. (1989) Functionalism and the Competition Model. In: MacWhinney, B. and Bates, E.A., Eds., The Cross-Linguistic Study of Sentence Processing, Cambridge University Press, Cambridge, UK, New York, 3-73.

[15] Grant, L. (2008) Adult Education. SIAST, Saskatoon.

[16] Ojose, B. (2008) Applying Piaget's Theory of Cognitive Development to Mathematics Instruction. The Mathematics Educator, 18, 26-30. 